\title{
RESEARCH AND SELECTION OF PROSPECTIVE MATERIALS FOR ACTIVATION DOSIMETRY OF INTENSE BREMSSTRAHLUNG RADIATION
}

\author{
DOlexii S. Deiev, (D) Roman M. Dronov, Valentyn A. Shevchenko, (D)Boris I. Shramenko* \\ National Science Center "Kharkov Institute of Physics and Technology" Kharkiv, Ukraine \\ *Corresponding Author: bshram@kipt.kharkov.ua \\ Received August 4, 2020; revised October 6, 2020; accepted November 2, 2020
}

Radiation technologies based on the use of powerful electron beams and gamma radiation are closely related to the need for dosimetry of these beams. Dosimetry based on the use of the inelastic gamma-ray scattering reaction on a number of nuclei with the formation of isomers with different half-lives and energies of radiation quanta is very successful for these purposes. An example of this application in dosimetry is the ${ }^{115} \mathrm{In}\left(\gamma, \gamma^{\prime}\right)^{115 \mathrm{~m}} \mathrm{In}$ reaction, which results in the formation of the ${ }^{115 \mathrm{~m}} \mathrm{In}$ isomer, having a gamma line with an energy of $336.24 \mathrm{keV}$ and a half-life of 4.5 hours. There was a successful application of this technique in dosimetry in solving certain practical problems (irradiation complexes based on ${ }^{60}$ Co source- cobalt "guns"). In this work, it is shown that the use of In detectors for dosimetry of gamma-radiation with a wide energy spectrum (bremsstrahlung) is associated with significant uncertainty in measuring the equivalent dose of the gamma spectrum with an upper limit of $10 \mathrm{MeV}$. This uncertainty is due to the relatively high threshold of the aforementioned reaction of $1.08 \mathrm{MeV}$. The quantitative contribution to the total radiation flux of the region of the gamma spectrum below the threshold $\left(\gamma, \gamma^{\prime}\right)$ of the reaction on the In nucleus was determined and it was shown that, depending on the direction of radiation, there is an systematic error in measuring the equivalent dose, reaching 20-60\%. Investigated and proposed for use alternative materials detectors, allowing reducing the systematic error in measuring the equivalent dose to $2-3 \%$, which is quite acceptable for practical use.

KEYWORDS: linear electron accelerator, gamma-radiation, $\left(\gamma, \gamma^{\prime}\right)$ reaction, isomer, dosimetry

\section{ОБГРУНТУВАННЯ НЕОБХІДНОСТІ ПОШУКУ НОВИХ МАТЕРІАЛІВ, ПЕРСПЕКТИВНИХ ДЛЯ ДОЗИМЕТРІЇ ГАММА-ВИПРОМІНЮВАННЯ ВЕЛИКОӤ ИНТЕНСИВНОСТИ}

Використання мішені 3 індію (In) для дозиметрії гамма-випромінювання по «наведеній» активності ізомеру ${ }^{115 \mathrm{~m}} \mathrm{In}$, що утворюється в реакції ${ }^{115} \operatorname{In}\left(\gamma, \gamma^{\prime}\right)^{115 \mathrm{~m}} \mathrm{In}$ описано, наприклад, в роботах [1,2], де такий метод дозиметрії був застосований для моніторингу гамма-випромінювання джерел на основі ізотопу ${ }^{60} \mathrm{Co}$ (кобальтових гармат) промислового застосування. Така методика була застосована для дозиметрії інтенсивних потоків гальмівного випромінювання більш високої енергії: $10-70$ МеВ. В роботах $[3,4]$ показано, що чутливість методу $\epsilon$ практично постійною в області енергій $10-70 \mathrm{MeB}$, що надзвичайно важливо. Визначено дозиметричний pecypc In детекторів (по тепловому навантаженню), що дорівнює $\approx 10^{7} \Gamma \mathrm{p}$, який при використанні додаткового охолодження може бути збільшений на 1-2 порядки. Таким чином, на додаток до даних робіт [5,6], показана можливість використання детекторів з In для дозиметрії інтенсивних потоків гаммаквантів в області енергій до $70 \mathrm{MeB}$

3 огляду на те, що енергія збудження ізомерного рівня ${ }^{115 \mathrm{~m}} \mathrm{In}$ дорівнює $1,08 \mathrm{MeB}$ (поріг $\left(\gamma, \gamma^{\prime}\right)$ реакції), проведено аналіз кількісного внеску ділянки спектра в інтервалі енергій 0-1,08 МеВ в загальний потік гаммавипромінювання $з$ верхньою межею діапазону $10 \mathrm{MeB}$. Для цього використано код GEANT4, PhysicsList G4LowEnergy і розраховані спектри гальмівних гамма-квантів і електронів для різних тілесних кутів реєстрації, на основі спектрів розраховані дозові характеристики гамма-випромінювання з верхньою межею діапазону 10 МeB. Розрахунки виконані для гальмівної мішені з танталу (Та), товщиною 2,4 мм і енергії електронів $10 \mathrm{MeB}$ (розподіл електронів - нормальний, $\mathrm{FWHM}=0,8 \mathrm{MeB}$, діаметр пучка 2 мм, що близько до реальних умов на прискорювачі ЛУЕ -10).

Конвертер 3 Та розташований у центрі сфери і показаний на Рис.1. Гальмівні кванти реєструються системою сферичних детекторів, відповідно до геометричної схеми, яка показана на Рис. 1б. Більш детально методика розрахунків в GEANT4 описана в [5].

Послідовність розрахунків потоків гальмівного випромінювання у залежності від кута вильоту (реєстрації) була наступною:

- поверхня сфери ділиться на сектори, кутова ширина яких відповідає кроку 0,1 радіан. $( \pm 0,05$ радіан або $\left.\pm 2,86^{\circ}\right)$;

- в центрі сфери знаходиться конвертор (радіатор) з Та розмірами $5 \times 5 \times 2,4$ мм;

- в кожному кутовому секторі підраховується число гамма-квантів $\mathrm{N}_{0-1,08}$ в інтервалі енергій 0-1,08 МеВ та загальна кількість гамма-квантів $\mathrm{N}_{\text {total }}$ в інтервалі енергій 0-10 МеB.

- розраховується відношення $\mathrm{N}_{0-1,08} / \mathrm{N}_{\text {total }}$ для різних кутів випромінювання.

В результаті математичного моделювання в GEANT4 отримані спектри гальмівного випромінювання для конвертора Та $5 \times 5 \times 2,4$ мм і енергії електронів $\mathrm{E}_{\mathrm{e}}=10 \mathrm{MeB}$. (Рис. 2). 


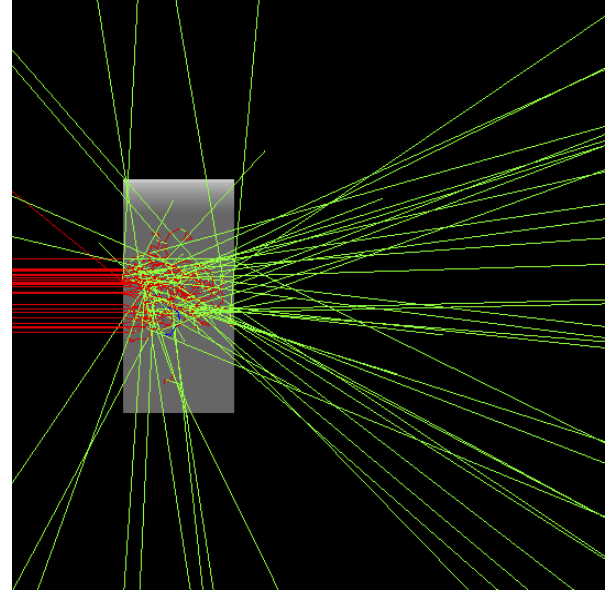

a

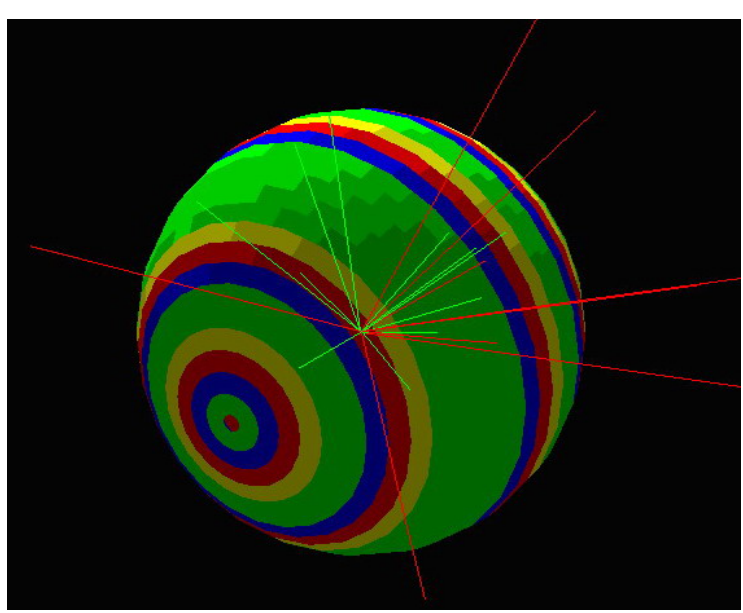

6

Рис. 1. Конвертер з Та - а, розташування сферичних детекторів, що реєструють виліт електронів (червоні лінії) і гаммаквантів (зелені лінії) - б. Крок по куту 0,1 радіан

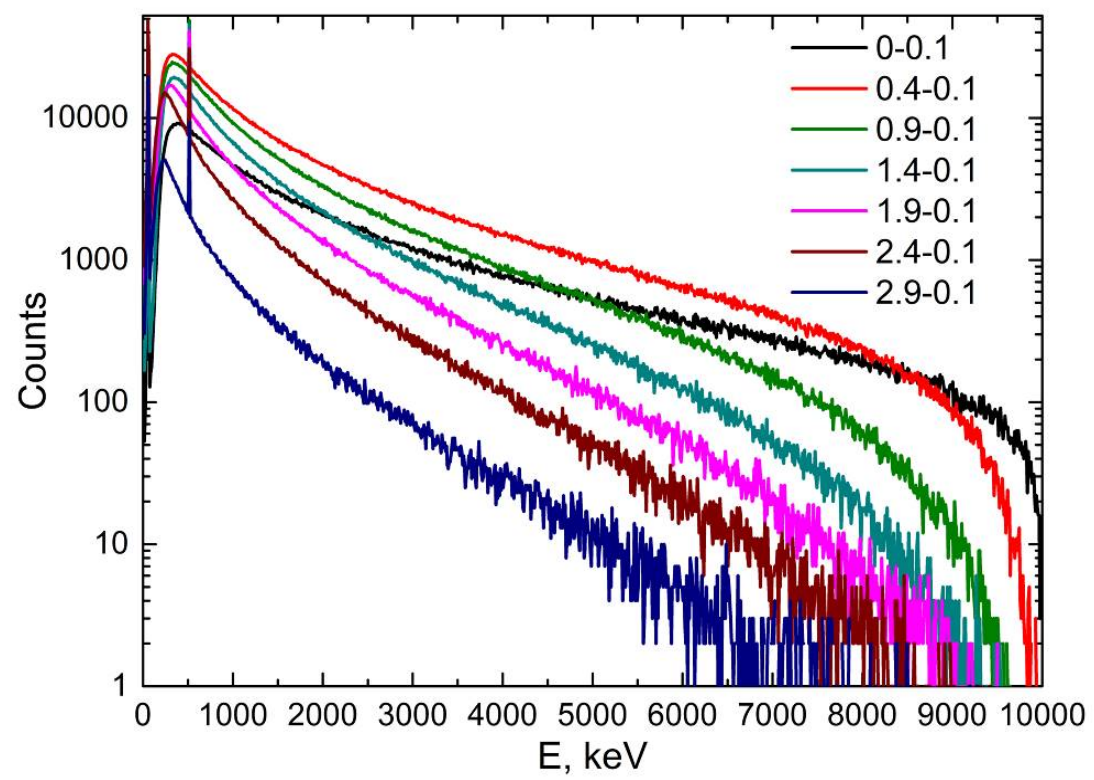

Рис. 2. Спектри гальмівних гамма-квантів для різних інтервалів кутів випромінювання (в радіанах). Ta $5 \times 5 \times 2,4$ мм, $\mathrm{E}_{\mathrm{e}}=10 \mathrm{MeB}$.

Як видно з Рис. 2, спектр гальмівного випромінювання істотно залежить від тілесного кута випромінювання (реєстрації). Загальна інтенсивність гальмівних спектрів різко падає зі збільшенням кута. Високоенергетична частина спектра в міру збільшення кута випромінювання зменшується значніше, ніж низькоенергетична частина. Наступним кроком було обчислення співвідношення $\mathrm{N}_{0-1.08} / \mathrm{N}_{\text {total }}$ для різних кутів випромінювання. Чисельні відношення кількості гамма-квантів в інтервалі енергій від 0 до1,08 МеВ - $\mathrm{N}_{0-1,08}$ до повного числа квантів в інтервалі енергій від 0 до $10 \mathrm{MeB}-\mathrm{N}_{\text {total }}$ для різних кутів випромінювання з інтервалом 0,1 рад подані в Таблиці 1.

Таблиця 1.

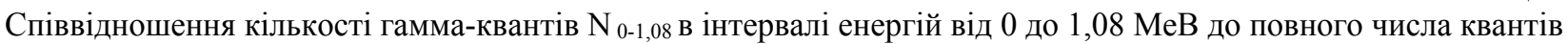
$\mathrm{N}_{\text {total }}$ для різних кутів випромінювання з інтервалом 0,1 рад. Та $5 \times 5 \times 2,4$ мм, $\mathrm{E}_{\mathrm{e}}=10 \mathrm{MeB}$.

\begin{tabular}{|c|c|c|}
\hline Кут середини смуги, рад & Кут середини смуги, град. & $\mathrm{N}_{0-1,08} / \mathrm{N}_{\text {total }}$ \\
\hline 0,05 & 2,86 & 0,463 \\
\hline 0,15 & 8,59 & 0,486 \\
\hline 0,25 & 14,32 & 0,509 \\
\hline 0,35 & 20,05 & 0,531 \\
\hline 0,45 & 25,78 & 0,550 \\
\hline 0,55 & 31,51 & 0,567 \\
\hline 0,65 & 37,24 & 0,583 \\
\hline
\end{tabular}




\begin{tabular}{|c|c|c|}
\hline Кут середини смуги, рад & Кут середини смуги, град. & $\mathrm{N}_{0-1,08} / \mathrm{N}_{\text {total }}$ \\
\hline 0,75 & 42,97 & 0,597 \\
\hline 0,85 & 48,70 & 0,607 \\
\hline 0,95 & 54,43 & 0,616 \\
\hline 1,05 & 60,16 & 0,624 \\
\hline 1,15 & 65,89 & 0,632 \\
\hline 1,25 & 71,62 & 0,639 \\
\hline 1,35 & 77,35 & 0,647 \\
\hline 1,45 & 83,08 & 0,653 \\
\hline 1,55 & 88,81 & 0,658 \\
\hline 1,65 & 94,54 & 0,672 \\
\hline 1,75 & 100,27 & 0,690 \\
\hline 1,85 & 106,00 & 0,707 \\
\hline 1,95 & 111,73 & 0,727 \\
\hline 2,05 & 117,46 & 0,745 \\
\hline 2,15 & 123,19 & 0,762 \\
\hline 2,25 & 128,92 & 0,776 \\
\hline 2,35 & 134,65 & 0,790 \\
\hline 2,45 & 140,38 & 0,800 \\
\hline 2,55 & 146,11 & 0,810 \\
\hline 2,65 & 151,84 & 0,818 \\
\hline 2,85 & 157,57 & 0,823 \\
\hline 2,95 & 163,30 & 0,828 \\
\hline 3,05 & 169,03 & 0,831 \\
\hline & 174,76 & 0,833 \\
\hline
\end{tabular}

Дані Табл. 1 показані у вигляді графіка на Рис. 3. Повна похибка розрахункових величин не перевищує 2\% і змінюється від $0,2 \%$ до 2\% зі збільшенням кута реєстрації від 0 до $180^{\circ}$.

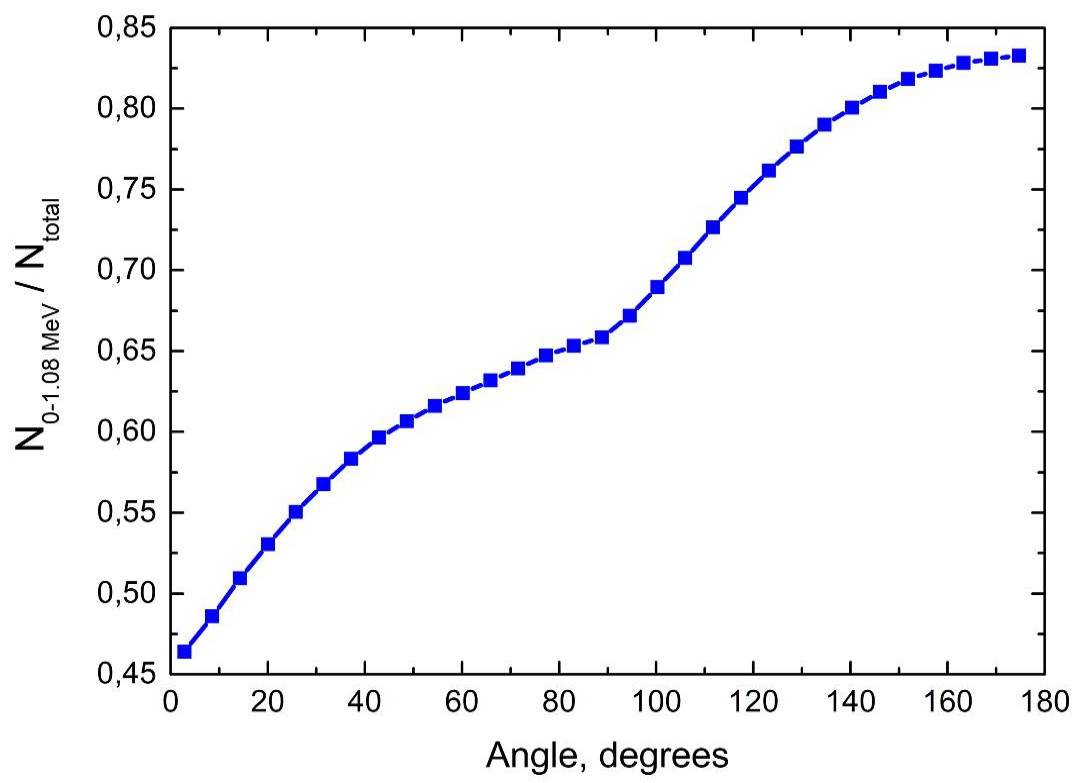

Рис. 3. Співвідношення кількості гальмівних квантів $\mathrm{N}_{0-1.08} / \mathrm{N}_{\text {total }}$ для різних кутів випромінювання (в градусах) Ta $5 \times 5 \times 2,4 \mathrm{~mm}, \mathrm{E}_{\mathrm{e}}=10 \mathrm{MeB}$.

Характерний прогин під кутом 90 градусів вказує на той факт, що під цим кутом мішень поглинає частину низькоенергетичних квантів, зменшуючи співвідношення числа гальмівних квантів. Істотним фактом $є$ те, що низькоенергетичне випромінювання в інтервалі 0-1,08 МеВ становить значну частку в загальному випромінюванні гамма-квантів, починаючи від значення близько 0,48 для кута 10 градусів, досягаючи величини 0,83 для кута 175 градусів.

В кінцевому підсумку нас цікавить інформація про дози, обумовлені гамма-квантами, і похибки у вимірюванні дози, які пов'язані з використанням детекторів 3 In. Для цього використані дані про «дозові коефіцієнти гамма-квантів», взяті з роботи [6], які наведені в Табл.2. 
Таблиця 2.

Питомі максимальні еквівалентні дози і еквівалентні дози для гамма-квантів різних енергій

\begin{tabular}{|c|c|c|c|}
\hline $\mathrm{E}_{\gamma}, \kappa е \mathrm{~B}$ & $\begin{array}{l}\text { Питома максимальна еквівалентна доза } \\
\qquad \mathrm{h}_{\mathrm{M}} ; \text { Зв } \times \mathrm{cm}^{2} / \text { фотон }\end{array}$ & Коефіциєнт якості; k & 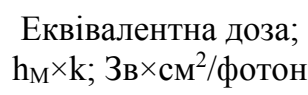 \\
\hline 5 & $6,50 \mathrm{E}-09$ & 2,6 & $1,69 \mathrm{E}-08$ \\
\hline 10 & $1,30 \mathrm{E}-09$ & 1,8 & $2,34 \mathrm{E}-09$ \\
\hline 20 & $2,60 \mathrm{E}-10$ & 1,4 & $3,64 \mathrm{E}-10$ \\
\hline 30 & $1,10 \mathrm{E}-10$ & 1,5 & $1,65 \mathrm{E}-10$ \\
\hline 50 & $5,20 \mathrm{E}-11$ & 1,7 & $8,84 \mathrm{E}-11$ \\
\hline 100 & $7,20 \mathrm{E}-11$ & 1,5 & $1,08 \mathrm{E}-10$ \\
\hline 200 & $1,20 \mathrm{E}-10$ & 1,2 & $1,44 \mathrm{E}-10$ \\
\hline 500 & $2,60 \mathrm{E}-10$ & 1,1 & $2,86 \mathrm{E}-10$ \\
\hline 1000 & $4,80 \mathrm{E}-10$ & 1,0 & $4,80 \mathrm{E}-10$ \\
\hline 2000 & $8,30 \mathrm{E}-10$ & 1,0 & $8,30 \mathrm{E}-10$ \\
\hline 5000 & $1,60 \mathrm{E}-09$ & 1,0 & $1,60 \mathrm{E}-09$ \\
\hline 10000 & $2,90 \mathrm{E}-09$ & 1,0 & $2,90 \mathrm{E}-09$ \\
\hline
\end{tabular}

Використовуючи дані Табл. 2, визначена залежність співвідношення дози для гамма-квантів в інтервалі 0-1,08 МеВ до повної дози в інтервалі 0-10 МеВ для всіх кутів випромінювання. Ці дані представлені в Табл. 3.

Таблиця 3.

Еквівалентні дози для різних енергетичних інтервалів і їх співвідношення в залежності від кута випромінювання для In

\begin{tabular}{|c|c|c|c|}
\hline $\begin{array}{c}\text { Кут середини смуги; } \\
\text { рад }\end{array}$ & $\begin{array}{l}\text { Доза } 0-1,08 \text { мэв; } \\
\text { Зв } \times \mathrm{cm}^{2} / \text { фотон }\end{array}$ & $\begin{array}{c}\text { Доза } 0-10 \text { Мэв; } \\
\text { Зв } \times \mathrm{cm}^{2} / \text { фотон }\end{array}$ & Доза 0-1,08 мэв / Доза 0-10 Мэв \\
\hline 0,05 & 0,020 & 0,098 & 0,198 \\
\hline 0,15 & 0,040 & 0,187 & 0,213 \\
\hline 0,25 & 0,049 & 0,210 & 0,231 \\
\hline 0,35 & 0,053 & 0,213 & 0,248 \\
\hline 0,45 & 0,055 & 0,206 & 0,266 \\
\hline 0,55 & 0,055 & 0,194 & 0,283 \\
\hline 0,65 & 0,054 & 0,181 & 0,299 \\
\hline 0,75 & 0,052 & 0,167 & 0,314 \\
\hline 0,85 & 0,050 & 0,152 & 0,327 \\
\hline 0,95 & 0,047 & 0,138 & 0,340 \\
\hline 1,05 & 0,044 & 0,127 & 0,351 \\
\hline 1,15 & 0,042 & 0,116 & 0,361 \\
\hline 1,25 & 0,040 & 0,107 & 0,371 \\
\hline 1,35 & 0,037 & 0,098 & 0,382 \\
\hline 1,45 & 0,035 & 0,089 & 0,390 \\
\hline 1,55 & 0,032 & 0,081 & 0,397 \\
\hline 1,65 & 0,031 & 0,075 & 0,413 \\
\hline 1,75 & 0,030 & 0,069 & 0,434 \\
\hline 1,85 & 0,029 & 0,065 & 0,454 \\
\hline 1,95 & 0,029 & 0,061 & 0,476 \\
\hline 2,05 & 0,028 & 0,056 & 0,497 \\
\hline 2,15 & 0,027 & 0,052 & 0,519 \\
\hline 2,25 & 0,026 & 0,048 & 0,538 \\
\hline 2,35 & 0,024 & 0,043 & 0,555 \\
\hline 2,45 & 0,022 & 0,038 & 0,569 \\
\hline 2,55 & 0,019 & 0,033 & 0,584 \\
\hline 2,65 & 0,016 & 0,027 & 0,596 \\
\hline 2,75 & 0,013 & 0,022 & 0,601 \\
\hline 2,85 & 0,010 & 0,016 & 0,609 \\
\hline 2,95 & 0,007 & 0,011 & 0,614 \\
\hline 3,05 & 0,003 & 0,005 & 0,618 \\
\hline
\end{tabular}


На Рис. 4. показані результати розрахунків співвідношення дози для гамма-квантів в інтервалі 0-1,08 МеВ до повної дози в інтервалі 0-10 МеВ в графічному вигляді.

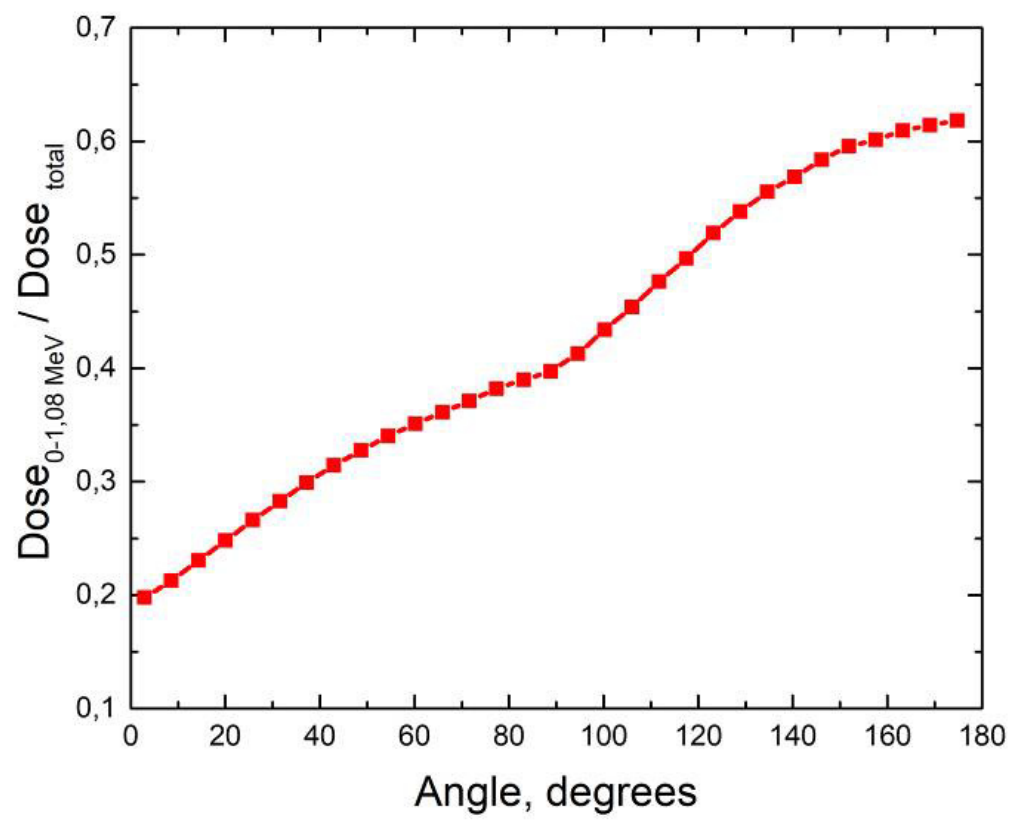

Рис. 4 Кутова залежність співвідношення еквівалентної дози низькоенергетичного гамма-випромінювання в інтервалі 0-1,08 МеВ до повної дози гамма-випромінювання в інтервалі 0-10 МеB для зразка In. Ta 5×5×2,4 мм, $\mathrm{E}_{\mathrm{e}}=10 \mathrm{MeB}$.

Аналізуючи дані, наведені в Табл. 3 і на Рис. 4 приходимо до висновку, що частка еквівалентної дози низькоенергетичного випромінювання в інтервалі 0-1,08 МеВ вносить значний вклад в загальну дозу у всьому інтервалі тілесних кутів випромінювання гамма-квантів з максимальною енергією 10 МеВ - від 20 до $60 \%$. Це, фактично, визначає систематичну похибку вимірювань дози за допомогою детекторів на основі In. Очевидно, що при використанні гамма-випромінювання 3 верхньою межею, що дорівнює кільком десяткам МеВ, невизначеність, обумовлена внеском інтервалу 0-1,08 МеВ, буде зменшуватися в міру збільшення верхньої межі діапазону, тобто для ситуацій, що мають місце в роботах [3, 4].

Збільшення верхньої межі діапазону пом'якшує ситуацію 3 невизначеністю при вимірюванні абсолютної поглиненої дози, але не знімає цю проблему повністю. Таким чином, використання детекторів на основі In для визначення абсолютних значень еквівалентної дози гамма-квантів 3 максимальною енергією 10 МеВ пов'язано з погрішностями від 20 до 60\%, хоча вимірювання відносних значень поглиненої дози цілком правомірні.

Виходом з цієї ситуації може бути пошук і використання таких активаційних детекторів, енергії збудження ізомерних рівнів яких, мають більш низькі значення в порівнянні з рівнем 1,08 МеB iзомера ${ }^{115 \mathrm{~m}} \mathrm{In}$, що дозволить забезпечити вимірювання дози випромінювання 3 меншою похибкою. Пошуку таких можливостей присвячені подальші дослідження.

\section{ВИБІР ПЕРСПЕКТИВНИХ МАТЕРІАЛІВ ДЛЯ АКТИВАЦІЙНОЇДОЗИМЕТРІЇ ГАЛЬМІВНОГО ВИПРОМІНЮВАННЯ ВЕЛИКОЇ ІНТЕНСИВНОСТІ}

При виборі нових матеріалів для активаційної дозиметрії гальмівного випромінювання головними критеріями були фізичні характеристики матеріалів і характеристики розпаду ізотопів, що утворюються.

Серед фізичних характеристик нових матеріалів, перш за все, необхідні:

- термостійкість;

- стійкість до високої потужності дози;

- висока максимальна доза.

Серед характеристик розпаду ізотопів що утворюються слід враховувати:

- мінімальне накопичення довгоживучих нуклідів;

- мінімальне значення енергії збудження ізомерного рівня;

- відносно короткий період напіврозпаду ізомера;

- високе значення перерізу $\left(\gamma, \gamma^{\prime}\right)$ реакції

В результаті ретельного відбору матеріалів-претендентів нашу увагу, перш за все, було зосереджено на матеріалах з низьким порогом збудження ізомерних станів ядер. Вони перераховані в Табл. 4.

Як видно з Табл. 4, до переліку ізомерів-претендентів були віднесені: ${ }^{111 \mathrm{~m}} \mathrm{Cd},{ }^{117 \mathrm{~m}} \mathrm{Sn},{ }^{135 \mathrm{~m}} \mathrm{Ba},{ }^{180 \mathrm{~m}} \mathrm{Hf}$. Були проведені експерименти 3 напрацювання очікуваних ізомерів за допомогою опромінення обраних зразків 
матеріалів пучком гальмівного випромінювання прискорювача ЛУЕ-10. Опромінення всіх зразків проводилося в стандартній геометрії опромінення з наступним режимом:

- енергія електронів $\mathrm{E}_{0}=11,5 \mathrm{MeB}$,

- тривалість експозиції 1,3 години,

- доза опромінення 4,8 кГр.

Таблиця 4.

Можливі реакції в перспективних мішенях

\begin{tabular}{|c|c|c|c|}
\hline Цільовий ізотоп & Реакція & Поріг реакції, МеэВ & Усереднений перетин, мбарн \\
\hline \multirow{2}{*}{${ }^{111} \mathrm{Cd}$} & ${ }^{112} \mathrm{Cd}(24 \%)(\gamma, \mathrm{n})^{111} \mathrm{Cd}$ & 9,80 & $100-120$ \\
\cline { 2 - 4 } & ${ }^{110} \mathrm{Cd}(12,5 \%)(\mathrm{n}, \gamma)^{111} \mathrm{Cd}$ & - & - \\
\hline \multirow{2}{*}{${ }^{111 \mathrm{~m}} \mathrm{Cd}$} & ${ }^{111} \mathrm{Cd}(12,8 \%)\left(\gamma, \gamma^{\prime}\right)^{111 \mathrm{~m}} \mathrm{Cd}$ & 0,40 & - \\
\hline \multirow{2}{*}{${ }^{115} \mathrm{Cd}$} & ${ }^{116} \mathrm{Cd}(7,5 \%)(\gamma, \mathrm{n})^{115} \mathrm{Cd}$ & 8,70 & $160-$ швидкі нейтрони; \\
\cline { 2 - 4 } & ${ }^{114} \mathrm{Cd}(28,7 \%)(\mathrm{n}, \gamma)^{115} \mathrm{Cd}$ & - & $\approx 350$ - теплові нейтрони \\
\hline \multirow{3}{*}{${ }^{117 \mathrm{~m}} \mathrm{Sn}$} & ${ }^{118} \mathrm{Sn}(24,2 \%)(\gamma, \mathrm{n})^{117 \mathrm{~m}} \mathrm{Sn}$ & 9,65 & $\leq 90$ \\
\cline { 2 - 4 } & ${ }^{116} \mathrm{Sn}(18,7 \%)(\mathrm{n}, \gamma)^{117 \mathrm{~m}} \mathrm{Sn}$ & - & - \\
\cline { 2 - 4 } & ${ }^{117} \mathrm{Sn}(7,3 \%)\left(\gamma, \gamma^{\prime}\right)^{117 \mathrm{~m}} \mathrm{Sn}$ & 0,32 & - \\
\hline \multirow{2}{*}{${ }^{135 \mathrm{~m}} \mathrm{Ba}$} & ${ }^{135} \mathrm{Ba}(6,5 \%)\left(\gamma, \gamma^{\prime}\right)^{135 \mathrm{~m}} \mathrm{Ba}$ & 0,30 & - \\
\cline { 2 - 4 } & ${ }^{136} \mathrm{Ba}(7,8 \%)(\gamma, \mathrm{n}){ }^{135 \mathrm{~m}} \mathrm{Ba}$ & $>9,00$ & - \\
\hline${ }^{180 \mathrm{~m}} \mathrm{Hf}$ & ${ }^{180} \mathrm{Hf}(29 \%)\left(\gamma, \gamma^{\prime}\right)^{180 \mathrm{~m}} \mathrm{Hf}$ & 1,10 & - \\
\hline${ }^{182 \mathrm{~m}} \mathrm{Hf}$ & ${ }^{186} \mathrm{~W}(29 \%)(\gamma, \alpha)^{182 \mathrm{~m}} \mathrm{Hf}$ & 1,00 & \\
\hline
\end{tabular}

Гамма-спектри опромінених зразків матеріалів наведені, відповідно, на Рис.5. - Рис.8.
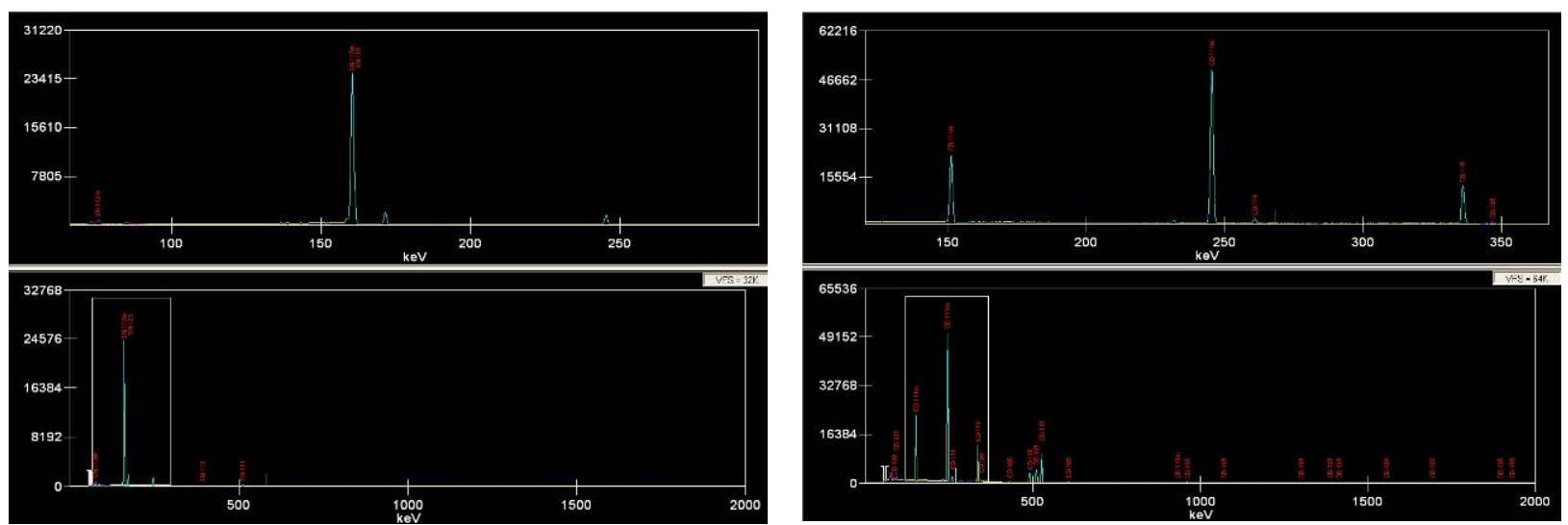

Рис. 5. Спектр опроміненого зразка $\mathrm{Sn}$

Рис 6. Спектр опроміненого зразка Сd
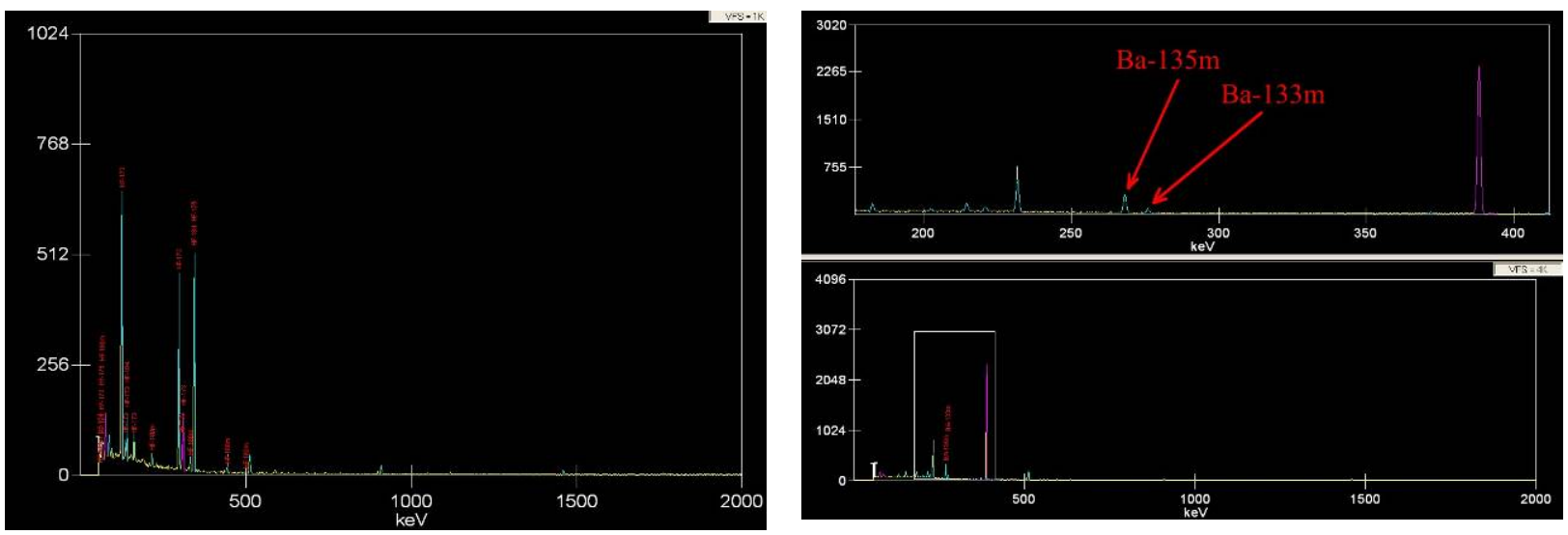

Рис. 7. Спектр опроміненого зразка $\mathrm{Hf}$

Рис. 8. Спектр опроміненого зразка Ва

Вимірювання активності цільових і домішкових ізотопів в опромінених зразках виконано за допомогою спектрометричного комплексу CANBERRA [5]. Узагальнені дані цільових i домішкових ізотопів в перспективних мішенях зведені в Табл. 5. 
Активність цільових і домішкових ізотопів в перспективних мішенях

Таблиця 5.

\begin{tabular}{|c|c|c|c|c|}
\hline Ізотоп & $\begin{array}{c}\text { Період } \\
\text { напіврозпаду, } \mathrm{T}_{1 / 2}\end{array}$ & $\begin{array}{c}\text { Гамма-лінія, } \\
\text { кеВ }\end{array}$ & $\begin{array}{c}\text { Активність, } \\
\text { кБк/г }\end{array}$ & $\begin{array}{c}\text { Невизначеність вимірювань, } \\
\kappa Б \kappa / \Gamma\end{array}$ \\
\hline${ }^{111 \mathrm{~m}} \mathbf{C d}$ & 49 хв & 245 & 243,000 & 1,600 \\
\hline$\overline{{ }^{105} \mathrm{Cd}}$ & $55 \mathrm{xB}$ & 961 & 60,000 & 5,000 \\
\hline${ }^{115} \mathrm{Cd}$ & 53 год & 527 & 45,000 & 12,000 \\
\hline${ }^{115 \mathrm{~m}} \mathrm{Cd}$ & 44,5 дня & 933 & 6,000 & 2,000 \\
\hline${ }^{113 \mathrm{~m}} \mathrm{Sn}$ & $21,4 \mathrm{xB}$ & 77,4 & 2,000 & 0,700 \\
\hline${ }^{117} \mathrm{Sn}$ & 13,6 днів & 158 & $\underline{33,800}$ & 1,200 \\
\hline$\overline{{ }^{123 \mathrm{~m}} \mathrm{Sn}}$ & 129 днів & 1088 & $\overline{<1,000}$ & - \\
\hline${ }^{123} \mathrm{Sn}$ & $40 \mathrm{XB}$ & 160 & $<1,000$ & - \\
\hline${ }^{133 m} \mathrm{Ba}$ & 38,9 год & 280 & 2,230 & 0,200 \\
\hline${ }^{135 m} \mathbf{B a}$ & 28,7 год & 270 & 14,600 & 0,700 \\
\hline${ }^{173} \mathrm{Hf}$ & 23,6 год & 123 & 1,300 & 0,900 \\
\hline${ }^{175} \mathrm{Hf}$ & 70 днів & 343 & 2,600 & 0,090 \\
\hline${ }^{180 \mathrm{~m}} \mathrm{Hf}$ & 5,5 год & 332 & 0,135 & 0,016 \\
\hline${ }^{184} \mathrm{Hf}$ & 4,1 год & $139 ; 345$ & 0,580 & 0,068 \\
\hline
\end{tabular}

Отримані результати 3 наведеної активності досліджуваних зразків після опромінення пучком гальмівного випромінювання (як видно з табл. 5), вказують на те, що за час опромінення зразків, найменшу активність має ізомер ${ }^{180 \mathrm{~m}} \mathrm{Hf} .3$ огляду також на той факт, що ізомер ${ }^{180 \mathrm{~m}} \mathrm{Hf}$ має порівняно високий поріг збудження $(1,1 \mathrm{MeB})$ - це дає підстави для виключення його 3 переліку перспективних ізотопів для активаційної дозиметрії.

Таким чином, в якості нових перспективних дозиметричних детекторів можуть бути використані наступні матеріали: $\mathrm{Cd}, \mathrm{Sn}, \mathrm{Ba}$. При опроміненні цих матеріалів гамма-квантами збуджуються ізомери 3 найбільш прийнятними для вимірювання і використання характеристиками $-{ }^{111 \mathrm{~m}} \mathrm{Cd} ;{ }^{117 \mathrm{~m}} \mathrm{Sn} ;{ }^{135 \mathrm{~m}} \mathrm{Ba}$. Доречно порівняти кутові залежності дозових відношень перспективних ізомерів 3 ізомером ${ }^{115 \mathrm{~m}} \mathrm{In}$. Таке порівняння демонструє Рис. 9.

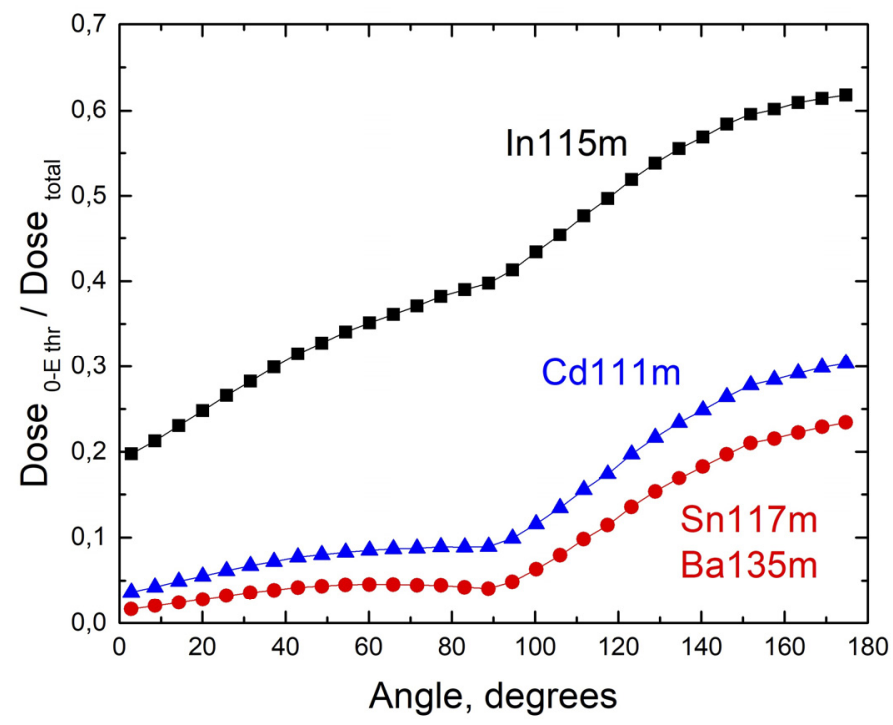

Рис. 9. Порівняння кутової залежності співвідношення еквівалентної дози низькоенергетичного гаммавипромінювання (від нуля до порога реакції) до повної дози в інтервалі 0-10 МеВ для різних ізомерів: $\left(0-1,08 \mathrm{MeB}-{ }^{115 \mathrm{~m}} \mathrm{In}\right) ;\left(0-0,4 \mathrm{MeB}-{ }^{111 \mathrm{~m}} \mathrm{Cd}\right) ;\left(0-0,32 \mathrm{MeB}-{ }^{117 \mathrm{~m}} \mathrm{Sn}\right) ;\left(0-0,3 \mathrm{MeB}-{ }^{135 \mathrm{~m}} \mathrm{Ba}\right)$.

3 Рис. 9 видно, що використання в якості дозиметричних детекторів $\mathrm{Cd}$, Sn або Ва дозволяє істотно знизити похибку у вимірюванні еквівалентної дози гамма-випромінювання в порівнянні з детектором з In для всіх кутів вильоту гамма-випромінювання. Наприклад, якщо при детектуванні гамма-випромінювання, спрямованого «вперед», похибка у вимірі дози детектором In становить 20\%, то для детекторів $\mathrm{Sn}$ i Ва, така похибка становить $2 \%$, а для детектора $\mathrm{Cd}-3 \%$. Таким чином, значення систематичних помилок у вимірі еквівалентної дози гамма-випромінювання детекторами Cd, Sn i Ba до 10 разів менше, ніж для детекторів з In, отже, вони більш прийнятні для практичного використання в якості нових, перспективних активаційних дозиметричних детекторів. 


\section{ВИСНОВКИ}

1. В результаті проведених досліджень характеристик матеріалу In, у якості дозиметричного детектора, отримані кількісні оцінки внеску інтенсивності низькоенергетичної частини гамма-випромінювання (в інтервалі енергій 0-1,08 MeB) в повну інтенсивність випромінювання з верхньою межею $10 \mathrm{MeB}$.

2. Показано, що використання для дозиметрії детекторів In пов'язано зі значними систематичними невизначеностями при вимірюванні еквівалентної дози гамма-випромінювання з верхньою межею $10 \mathrm{MeB}$, які досягають 20-60\% (в залежності від кута випромінювання).

3. Проведено аналіз фізичних характеристик різних матеріалів і характеристик можливих ізомерних станів ядер, які придатні в якості перспективних детекторів для дозиметрії потоків гамма-випромінювання високої інтенсивності.

4. На основі експериментальних даних про величину активності, отриману після опромінення обраних для дослідження зразків пучками гальмівного випромінювання лінійного прискорювача ЛУЕ-10, зроблено вибір матеріалів-детекторів, найбільш придатних для активаційної дозиметрії гамма-випромінювання.

5. Показано, що в якості дозиметричних детекторів, найбільш придатними матеріалами $€: \mathrm{Cd}, \mathrm{Sn}$ i Ba, при опроміненні яких збуджуються відповідні ізомери 3 прийнятними для вимірювань характеристиками: ${ }^{111 \mathrm{~m}} \mathrm{Cd}$; ${ }^{117 \mathrm{~m}} \mathrm{Sn} ;{ }^{135 \mathrm{~m}} \mathrm{Ba}$.

6. Використання в якості дозиметричних активаційних детекторів $\mathrm{Cd}$, Sn i Ва дозволяе знизити систематичну помилку в вимірі еквівалентної дози гамма-випромінювання до 2-3\%. Так як період напіврозпаду ізомеру ${ }^{111 \mathrm{~m}} \mathrm{Cd}$ (49 хвилин), є найбільш відповідним для вимірювань в порівнянні 3 періодами напіврозпаду ізомерів ${ }^{117 \mathrm{~m}} \mathrm{Sn}$; ${ }^{135 \mathrm{~m}} \mathrm{Ba}$, можна зробити висновок про те, що матеріал $\mathrm{Cd} \epsilon$ найбільш прийнятним для практичного використання в якості активаційного дозиметричного детектора.

\section{ПОДЯКА}

Автори висловлюють подяку Г.Д. Пугачову за допомогу в зборі даних по «дозовим коефіцієнтам гамма-квантів».

\section{ORCID IDs}

Olexii S. Deiev, https://orcid.org/0000-0003-4565-9039; (Doman N. Dronov, https://orcid.org/0000-0002-1824-835X,

(D)Boris I. Shramenko, https://orcid.org/0000-0003-4583-6963

\section{СПИСОК ЛІТЕРАТУРИ}

[1] Jiunn-Hsing Chao, Pin-Chieh Hsu, and Hong-Ming Liu, Applied Radiation and Isotopes, 55, 549-556 (2001), https://doi.org/10.1016/S0969-8043(01)00076-8.

[2] A. Murataka, S. Endo, Y. Kojima, and K. Shizuma, J. Radiat. Res. 51(2), 197-203 (2010), https://doi.org/10.1269/jrr.09083.

[3] V.I. Nikiforov, A.Eh. Tenishev, A.V. Torgovkin, V.L. Uvarov, V.A. Shevchenko, I.N. Shlyahov, and B.I. Shramenko, Problems of Atomic Science and Technology, 4(80), 181-184, https://vant.kipt.kharkov.ua/ARTICLE/VANT_2012_4/article_2012_4_181.pdf. (In Russian).

[4] Ju.V. Rogov, V.A. Shevchenko, I.N. Shlyakhov, B.I. Shramenko, A.Eh. Tenishev, A.V. Torgovkin, V.L. Uvarov, and V.F. Zhiglo, Problems of Atomic Science and Technology, 6(100), 120-124 (2015), https://vant.kipt.kharkov.ua/ARTICLE/VANT_2015 6/article 2015 6_120.pdf.

[5] J.H. Chao, and A.C. Chiang, Radiation Measurements, 45(9), 1024-1033 (2010), https://doi.org/10.1016/j.radmeas.2010.08.012.

[6] A.A. Lychagin, E.V. Koryakina, and S.E. Ulyanenko, Meditsinskaya Fizika, 3, 15-23 (2015), http://medphys.amphr.ru/_private/DB/67_15.pdf. (in Russian)

[7] A.N. Dovbnya, O.S. Deyev, V.A. Küshnir, V.S. Malyshevsky, T.V. Malykhina,V.V. Mitrochenko, S.A. Perezhogin, A.V. Torgovkin, G.V. Fomin, and B.I. Shramenko, Problems of Atomic Science and Technology, 6(88), 192-195, (2013), https://vant.kipt.kharkov.ua/ARTICLE/VANT_2013_6/article_2013_6_192.pdf.

[8] Нормы радиационной безопасности НРБ-7б/87 [R Radiation safety standards NRB-76/87], (Energoizdat, Moscow, 1988).

\section{ДОСЛІДЖЕННЯ ТА ВИБІР ПЕРСПЕКТИВНИХ МАТЕРІАЛІВ ДЛЯ АКТИВАЦЙНОЇ ДОЗИМЕТРІЇ ГАЛЬМІВНОГО ВИПРОМІНЮВАННЯ ВЕЛИКОЇ ІНТЕНСИВНОСТІ \\ О.С. Десв, Р.М. Дронов, В.А. Шевченко, Б.І. Шраменко}

Національний Науковий Центр «Харківський фізико-технічний інститут»

1 вул. Академічна, м. Харків Украӥна 61108

Радіаційні технології, засновані на застосуванні потужних пучків електронів та гамма-випромінювання тісно пов'язані 3 необхідністю дозиметрії цих пучків. Вельми успішною для цих цілей є дозиметрія, заснована на використанні реакції непружного розсіювання гамма-квантів на цілому ряді ядер з утворенням ізомерів 3 різними періодами напіврозпаду і енергіями квантів випромінювання. Прикладом такого застосування в дозиметрії $\epsilon$ реакція ${ }^{115}$ In $\left(\gamma, \gamma^{\prime}\right)^{115 m}$ In в результаті якої утворюється ізомер ${ }^{115 \mathrm{~m}} \mathrm{In}$, що має гамма-лінію з енергією 336,24 кеВ і період напіврозпаду 4,5 годин. Мало місце успішне застосування цієї методики в дозиметрії при вирішенні певних практичних завдань (опромінювальні комплекси на основі джерел ${ }^{60} \mathrm{Co}$ - кобальтові «гармати»). У даній роботі показано, що використання детекторів 3 In для дозиметрії гаммавипромінювання з широким енергетичним спектром (гальмівне випромінювання) пов'язане зі значною невизначеністю при вимірюванні еквівалентної дози гамма-спектра з верхньою межею 10 МеВ. Така невизначеність обумовлена відносно високим порогом вищезгаданої реакції $-1,08 \mathrm{MeB.} \mathrm{В} \mathrm{даній} \mathrm{роботі} \mathrm{визначено} \mathrm{кількісний} \mathrm{вклад} \mathrm{у} \mathrm{повний} \mathrm{потік}$ випромінювання ділянки гамма-спектра нижче порогу ( $\left.\gamma, \gamma^{\prime}\right)$ реакції на ядрі In та показано, що в залежності від напрямку випромінювання має місце систематична похибка при вимірюванні еквівалентної дози, що досягає 20-60\%. Досліджено та 
запропоновано для використання альтернативні матеріали - детектори, що дозволяють зменшити систематичну похибку при вимірі еквівалентної дози до 2-3\%, що є цілком прийнятним для практичного застосування.

КЛЮЧОВІ СЛОВА: лінійний прискорювач електронів, гамма-випромінювання, $\left(\gamma, \gamma^{\prime}\right)$ реакція, ізомер, дозиметрія

\section{ИССЛЕДОВАНИЯ И ВЫБОР ПЕРСПЕКТИВНЫХ МАТЕРИАЛОВ ДЛЯ АКТИВАЦИОННОЙ ДОЗИМЕТРИИ ТОРМОЗНОГО ИЗЛУЧЕНИЯ БОЛЬШОЙ ИНТЕНСИВНОСТИ \\ О.С. Деев, Р.М. Дронов, В.А. Шевченко, Б.И. Шраменко \\ Национальный Научный Центр «Харьковский физико-технический институт» \\ 1 ул. Академическая, Харьков Украина 61108}

Радиационные технологии, основанные на применении мощных пучков электронов и гамма-излучения, тесно связаны с необходимостью дозиметрии этих пучков. Весьма успешной для этих целей является дозиметрия, основанная на использовании реакции неупругого рассеяния гамма-квантов на целом ряде ядер с образованием изомеров с различными периодами полураспада и энергиями квантов излучения. Примером такого применения в дозиметрии является реакция ${ }^{115} \operatorname{In}\left(\gamma, \gamma^{\prime}\right)^{115 \mathrm{~m}} \mathrm{In}$ в результате которой образуется изомер ${ }^{115 \mathrm{~m}} \mathrm{In}$, имеющий гамма-линию с энергией 336,24 кэВ и период полураспада 4,5 часа. Имело место успешное применение этой методики в дозиметрии при решении определенных практических задач (облучательные комплексы на основе источников ${ }^{60} \mathrm{Co}-$ кобальтовые «пушки»). В настоящей работе показано, что использование детекторов из In для дозиметрии гамма-излучения с широким энергетическим спектром (тормозное излучение) сопряжено со значительной систематической ошибкой в измерении эквивалентной дозы гаммаспектра с верхней границей 10 МэВ. Такая неопределенность обусловлена относительно высоким порогом вышеупомянутой реакции $-1,08$ МэВ. В работе определен количественный вклад в полный поток излучения участка гамма-спектра ниже порога $\left(\gamma, \gamma^{\prime}\right)$ реакции на ядре In. Показано, что в зависимости от направления излучения имеет место систематическая ошибка в измерении эквивалентной дозы, достигающая 20-60\%. Исследованы и предложены для использования альтернативные материалы - детекторы, позволяющие уменьшить систематическую ошибку в измерении эквивалентной дозы до 2-3\%, что является вполне приемлемым для практического применения.

КЛЮЧЕВЫЕ СЛОВА: линейный ускоритель электронов, гамма-излучение, $\left(\gamma, \gamma^{\prime}\right)$ реакция, изомер, дозиметрия 